\title{
Demirjian Stage Tooth Formation Results from a Large Group of Children
}

\author{
Helen M. Liversidge
}

\begin{abstract}
Queen Mary University of London, Barts and The London School of Medicine and Dentistry, London, United Kingdom
\end{abstract}

ABSTRACT The aim of this study is to present further data on the timing and variation of individual permanent mandibular teeth using Demirjian stages from a large collaboration. Seven mandibular permanent teeth were assessed from dental radiographs of healthy dental patients from Australia, Belgium, Canada, England, Finland, France, South Korea and Sweden (cross-sectional study; $\mathrm{n}=9,371,4,710$ males, 4,661 females; aged 2-18). Data are presented in three ways, namely by tooth stage for males, females, and pooled sex. Mean age at entry of each tooth formation stage (maturity data) was calculated

Many studies of dental maturation during the last 50 years have described the timing of permanent tooth formation stages. Several reports remain important because they include very young children and follow individuals longitudinally (Moorrees et al., 1963) or use clearly defined stages and a large sample (Demirjian et al., 1973; Demirjian and Goldstein, 1976; Demirjian and Levesque, 1980; Demirjian, 1994), although none give full descriptive results. The ease of statistical analyses and a better understanding of age estimation have highlighted the lack of descriptive data of the timing of tooth formation stages. This paper presents detailed results from a collaboration of published cross-sectional studies organised by Nils Chaillet in Canada that has resulted in several published reports including a polynomial approach to Demirjian's dental maturity scale (Chaillet et al., 2004; Chaillet et al., 2005) and maturity data of individual tooth stages (Liversidge et al., 2006). Tooth formation data are presented here in different formats to assess maturity and estimate age using developing teeth in living children, in forensic cases, or in archaeological cases where sex is uncertain.

\section{MATERIAL AND METHODS}

Tooth formation data from dental radiographs using Demirjian stages (Demirjian et al., 1973; 1976; Demirjian, 1994) were combined to form the International Data Base. The sample consisted of cross-sectional data from published studies from Finland, Sweden, England, Korea, Belgium, Australia, Belgium, Canada and France (Nyström et al., 1986; Nyström et al., 1988; Kataja et al., 1989; Liversidge and Speechly, 2001; Teivens and Mörnstad, 2001; Willems et al., 2001; McKenna et al., 2002; Chaillet and Demirjian, using logistic regression and modified for age prediction. The $51 \%$ confidence interval for age within stage of individual tooth stages was calculated for use in forensic age estimation where the burden of proof is on the balance of probabilities. Average age, standard deviation, standard error, 3rd and 97th percentile within tooth stage was calculated from a uniform age sample (171 for each year of age from 3 to $16, \mathrm{n}=2,394)$. Modified maturity data and average age within stage from the uniform age distribution are two new methods of age estimation. Dental Anthropology 2010;23(1):16-23.

2004). The sample studied in this paper, after cleaning was radiographic data from 4,710 males and 4,661 females aged 2 to 18 (when all individuals had reached second molar maturity) shown in Figure 1 (left). Previous results of the timing of Demirjian tooth stages of individual teeth are available for males and females for each group separately (Finland, Sweden, England, Korea, Belgium, Australia, Belgium, Canada and France) and for all groups combined for individuals from age 2 up to and including 16 years of age (Table 9 in Liversidge et al., 2006).

Mean age of entering a tooth stage was calculated by logistic regression for males, females and sexes combined (Table 1). Logistic regression calculates the average age at entry of a specific formation stage and represents the age when half of children at that age, have reached or passed the stage (Taranger, 1976; Eveleth and Tanner, 1990; Cameron, 2004) and is similar to probit regression used to calculate mean age of tooth eruption (Liversidge, 2003). In this regard the mean age is identical to median age, half of children enter the stage prior to mean age, and half enter subsequent to mean age. This is an appropriate method to compare maturation between groups; it is not equivalent to the mean or median age of a child in the specific maturity stage (see below). Maturity data were modified for each stage of each developing tooth (Table 2) by adding half the interval to the next stage (see Smith, 1991). The second way of presenting results is the $51 \%$ confidence interval of age

Correspondence to: Helen M. Liversidge, Institute of Dentistry, Turner Street, E1 2AD, London, United Kingdom

Email: h.m.liversidge@qmul.ac.uk 

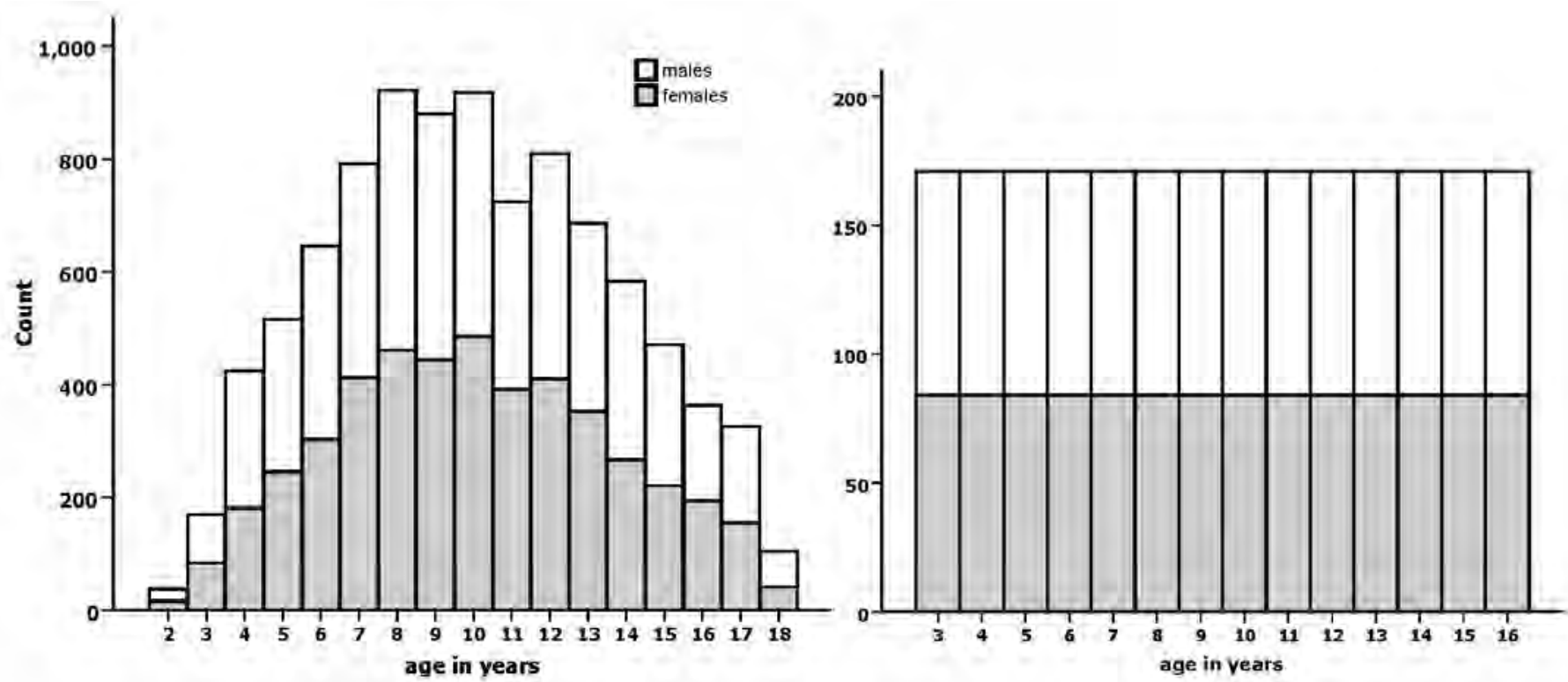

Fig. 1. Age and sex of radiographic sample (left), selected group for a uniform age distribution (right).

for each individual tooth stage. This was calculated using the 24.5th and 75.5th percentiles of average age within stage (Table 10 from Liversidge et al., 2006) and is shown in Table 3. This is slightly greater than the inter-quartile range and just over half of individuals in the specific stage will fall within this interval. The third way data are presented is average age within stage from a uniform age sample. The age cohort with the lowest number of children was 171 for three year olds ( 87 male, 84 female) and 87 males and 84 females were randomly selected from each year of age from 3 to 16 (total n 2,394, Figure 1 right). Descriptive statistics of age within individual tooth formation stages, including 3rd and 97th percentiles (using the normal deviate, see Cole, 2002) were calculated from this group and are shown in Table 4. This is referred to as L10a in Liversidge et al. (2010) in a comparison of dental age estimation methods using the same target sample of Maber et al. (2006).

\section{RESULTS AND DISCUSSION}

Maturity data representing the average age entering a tooth formation stage (age when half of children have reached or passed the stage) are shown in Table 1 . The ages when $3 \%$ and $97 \%$ of girls and boys had entered some stages including D (crown complete with initial root) and $\mathrm{H}$ (mature apex) are shown in Figure 2. The left and right hand edges of the open diamond are the ages when 3\% and $97 \%$ of girls had reached or passed this stage. Filled diamonds are data for boys. The sex difference is smaller for earlier stages and greatest for stage $\mathrm{H}$ (mature apex) of the canine. This is the only appropriate measure of the final maturity stage. Smoothed cumulative frequency distribution curves are shown for M2 stages in Figure 3. This is the only tooth in this study where data are available from crypt stage to mature apex; however the variation for early tooth stages is probably unrepresentative as this collaborative study includes only 38 two year olds. Maturity data modified for age prediction are shown in Table 2 (referred to as L9a in Liversidge et al., submitted). Once a tooth reaches the most mature stage (apex closed with mature periodontal ligament width) age cannot be estimated using development and this stage is omitted from tables of modified maturity data and within stage data. The second type of result is the $51 \%$ confidence interval (Table 3, Figure 4) similar to what Koningsberg et al. (2008) term 'coverage'. This interval is useful when estimating age in forensic cases where the burden of proof is on the balance of probabilities. Coverage also

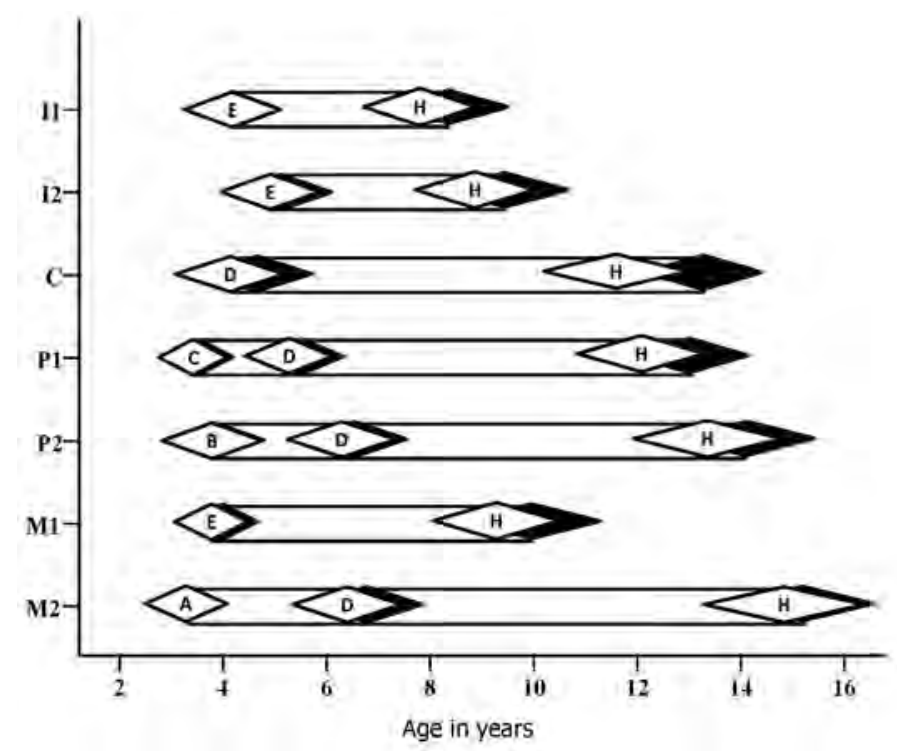

Fig. 2. Timing of some Demirjian tooth stages including $\mathrm{D}$ (crown complete with initial root) and $\mathrm{H}$ (mature apex). Diamond extends from 3rd to 97th percentile, apex is mean age. Open diamonds females, solid diamonds males. 
TABLE 1. Mean age of entering Demirjian tooth stages for mandibular permanent teeth recalculated from cleaned data using logistic regression of 4,710 males and 4,661 females ${ }^{1}$

\begin{tabular}{|c|c|c|c|c|c|c|c|}
\hline \multirow{2}{*}{$\begin{array}{l}\text { Mandibular } \\
\text { Tooth }\end{array}$} & \multirow[b]{2}{*}{ Grade } & \multicolumn{2}{|c|}{ Males Alone } & \multicolumn{2}{|c|}{ Females Alone } & \multicolumn{2}{|c|}{ Sexes Pooled } \\
\hline & & $\begin{array}{l}\text { Mean for } \\
\text { prediction }\end{array}$ & $\mathrm{sd}$ & $\begin{array}{l}\text { Mean for } \\
\text { prediction }\end{array}$ & $\mathrm{sd}$ & $\begin{array}{l}\text { Mean for } \\
\text { prediction }\end{array}$ & sd \\
\hline \multirow[t]{4}{*}{ I1 } & $\mathrm{E}$ & 4.39 & 0.44 & 4.24 & 0.42 & 4.33 & 0.43 \\
\hline & $\mathrm{F}$ & 6.02 & 0.38 & 5.70 & 0.36 & 5.88 & 0.38 \\
\hline & G & 6.97 & 0.40 & 6.68 & 0.37 & 6.82 & 0.39 \\
\hline & $\mathrm{H}$ & 8.35 & 0.60 & 7.84 & 0.57 & 8.09 & 0.60 \\
\hline \multirow[t]{4}{*}{$\mathrm{I} 2$} & $\mathrm{E}$ & 5.21 & 0.47 & 4.87 & 0.42 & 5.05 & 0.46 \\
\hline & $\mathrm{F}$ & 6.68 & 0.38 & 6.28 & 0.37 & 6.49 & 0.39 \\
\hline & G & 7.82 & 0.47 & 7.32 & 0.44 & 7.56 & 0.47 \\
\hline & $\mathrm{H}$ & 9.41 & 0.65 & 8.79 & 0.59 & 9.09 & 0.65 \\
\hline \multirow[t]{5}{*}{ C } & D & 4.75 & 0.59 & 4.19 & 0.53 & 4.49 & 0.59 \\
\hline & $\mathrm{E}$ & 6.60 & 0.45 & 5.99 & 0.44 & 6.31 & 0.47 \\
\hline & $\mathrm{F}$ & 8.51 & 0.51 & 7.59 & 0.50 & 8.04 & 0.56 \\
\hline & G & 11.04 & 0.61 & 9.84 & 0.56 & 10.42 & 0.67 \\
\hline & $\mathrm{H}$ & 13.23 & 0.64 & 11.73 & 0.68 & 12.47 & 0.80 \\
\hline \multirow[t]{6}{*}{ P1 } & C & 3.58 & 0.40 & 3.41 & 0.35 & 3.49 & 0.39 \\
\hline & D & 5.56 & 0.43 & 5.28 & 0.41 & 5.43 & 0.43 \\
\hline & $\mathrm{E}$ & 7.26 & 0.49 & 6.78 & 0.43 & 7.02 & 0.48 \\
\hline & $\mathrm{F}$ & 9.19 & 0.53 & 8.70 & 0.49 & 8.94 & 0.53 \\
\hline & G & 11.44 & 0.62 & 10.70 & 0.58 & 11.05 & 0.63 \\
\hline & $\mathrm{H}$ & 13.03 & 0.64 & 12.27 & 0.65 & 12.64 & 0.69 \\
\hline \multirow[t]{7}{*}{ P2 } & B & 3.81 & 0.57 & 3.80 & 0.55 & 3.81 & 0.56 \\
\hline & C & 4.94 & 0.55 & 4.81 & 0.55 & 4.89 & 0.55 \\
\hline & D & 6.48 & 0.57 & 6.21 & 0.56 & 6.35 & 0.57 \\
\hline & $\mathrm{E}$ & 8.02 & 0.58 & 7.62 & 0.64 & 7.82 & 0.62 \\
\hline & $\mathrm{F}$ & 9.83 & 0.69 & 9.35 & 0.60 & 9.58 & 0.65 \\
\hline & G & 12.26 & 0.75 & 11.57 & 0.71 & 11.90 & 0.76 \\
\hline & $\mathrm{H}$ & 14.09 & 0.73 & 13.44 & 0.76 & 13.77 & 0.78 \\
\hline \multirow[t]{4}{*}{ M1 } & $\mathrm{E}$ & 3.99 & 0.32 & 3.81 & 0.38 & 3.91 & 0.35 \\
\hline & $\mathrm{F}$ & 5.46 & 0.41 & 5.21 & 0.41 & 5.35 & 0.42 \\
\hline & G & 6.84 & 0.48 & 6.42 & 0.45 & 6.64 & 0.46 \\
\hline & $\mathrm{H}$ & 9.95 & 0.71 & 9.33 & 0.68 & 9.64 & 0.71 \\
\hline \multirow[t]{9}{*}{ M2 } & $\mathrm{O}$ & 3.40 & 0.30 & 2.92 & 0.51 & 3.19 & 0.40 \\
\hline & A & 3.46 & 0.33 & 3.33 & 0.42 & 3.40 & 0.37 \\
\hline & B & 3.97 & 0.33 & 3.72 & 0.46 & 3.87 & 0.38 \\
\hline & C & 4.91 & 0.44 & 4.85 & 0.44 & 4.88 & 0.42 \\
\hline & $\mathrm{D}$ & 6.79 & 0.52 & 6.43 & 0.54 & 6.61 & 0.54 \\
\hline & $\mathrm{E}$ & 8.80 & 0.56 & 8.48 & 0.52 & 8.64 & 0.55 \\
\hline & $\mathrm{F}$ & 10.68 & 0.60 & 10.12 & 0.56 & 10.39 & 0.60 \\
\hline & G & 12.18 & 0.60 & 11.57 & 0.60 & 11.86 & 0.63 \\
\hline & $\mathrm{H}$ & 15.22 & 0.71 & 14.75 & 0.77 & 14.99 & 0.75 \\
\hline
\end{tabular}

${ }^{1}$ These statistics represent the age when half of children have reached or passed the stage. Code O refers to crypt formation prior to evidence of tooth mineralization.

provides a means to test if a target sample is representative Results of this type from this study are shown in Table 4 (Konigsberg et al., 2008); 24.5\% should fall below the and are referred to as L10a in Liversidge et al. (submitted). interval, $51 \%$ within the interval and $24.5 \%$ above. The This flat age distribution, together with an adequate third type of result is average age within stage from a sample size and wide age range, are important features of uniform age distribution (similar number of individuals a reference sample that contribute to accuracy (Konigsberg in each age category). Konigsberg and Frankenberg (1992) and Frankenberg, 2002; Konigsberg et al., 2008).

suggest that age could be more accurately estimated using Understanding how maturity data differ to within stage a reference sample based on a uniform age distribution. data is challenging and Figure 5 illustrates some of these 
TABLE 2. Maturity data modified for age prediction for mandibular permanent tooth stages

\begin{tabular}{|c|c|c|c|c|c|c|c|}
\hline \multirow[b]{2}{*}{$\begin{array}{l}\text { Mandibular } \\
\text { Tooth }\end{array}$} & \multirow[b]{2}{*}{ Grade } & \multicolumn{2}{|c|}{ Males Alone } & \multicolumn{2}{|c|}{ Females Alone } & \multicolumn{2}{|c|}{ Sexes Pooled } \\
\hline & & $\begin{array}{l}\text { Mean for } \\
\text { prediction }\end{array}$ & $\mathrm{sd}$ & $\begin{array}{l}\text { Mean for } \\
\text { prediction }\end{array}$ & $\mathrm{sd}$ & $\begin{array}{l}\text { Mean for } \\
\text { prediction }\end{array}$ & $\mathrm{sd}$ \\
\hline \multirow[t]{3}{*}{ I1 } & E & 5.24 & 0.44 & 5.01 & 0.42 & 5.11 & 0.43 \\
\hline & $\mathrm{F}$ & 6.48 & 0.38 & 6.18 & 0.36 & 6.35 & 0.38 \\
\hline & G & 7.64 & 0.40 & 7.29 & 0.37 & 7.45 & 0.39 \\
\hline \multirow[t]{3}{*}{ I2 } & $\mathrm{E}$ & 5.94 & 0.47 & 5.62 & 0.42 & 5.77 & 0.46 \\
\hline & $\mathrm{F}$ & 7.20 & 0.38 & 6.86 & 0.37 & 7.02 & 0.39 \\
\hline & G & 8.56 & 0.47 & 8.06 & 0.44 & 8.32 & 0.47 \\
\hline \multirow[t]{4}{*}{$\mathrm{C}$} & D & 5.68 & 0.59 & 5.09 & 0.53 & 5.40 & 0.59 \\
\hline & $\mathrm{E}$ & 7.64 & 0.45 & 6.83 & 0.44 & 7.18 & 0.47 \\
\hline & $\mathrm{F}$ & 9.86 & 0.51 & 8.76 & 0.50 & 9.23 & 0.56 \\
\hline & G & 12.14 & 0.61 & 10.80 & 0.56 & 11.44 & 0.67 \\
\hline \multirow[t]{5}{*}{ P1 } & C & 4.61 & 0.40 & 4.37 & 0.34 & 4.46 & 0.39 \\
\hline & D & 6.34 & 0.43 & 5.99 & 0.41 & 6.22 & 0.43 \\
\hline & $\mathrm{E}$ & 8.20 & 0.49 & 7.82 & 0.43 & 7.98 & 0.48 \\
\hline & $\mathrm{F}$ & 10.32 & 0.53 & 9.83 & 0.49 & 10.00 & 0.53 \\
\hline & G & 12.24 & 0.62 & 11.49 & 0.58 & 11.84 & 0.63 \\
\hline \multirow[t]{6}{*}{ P2 } & B & 4.41 & 0.57 & 4.30 & 0.54 & 4.34 & 0.56 \\
\hline & C & 5.62 & 0.55 & 5.46 & 0.55 & 5.62 & 0.55 \\
\hline & $\mathrm{D}$ & 7.16 & 0.57 & 6.86 & 0.56 & 7.08 & 0.57 \\
\hline & $\mathrm{E}$ & 8.90 & 0.58 & 8.48 & 0.64 & 8.70 & 0.62 \\
\hline & $\mathrm{F}$ & 11.04 & 0.69 & 10.50 & 0.60 & 10.74 & 0.65 \\
\hline & G & 13.19 & 0.75 & 12.56 & 0.71 & 12.84 & 0.76 \\
\hline \multirow[t]{3}{*}{ M1 } & $\mathrm{E}$ & 4.80 & 0.32 & 4.58 & 0.38 & 4.63 & 0.35 \\
\hline & $\mathrm{F}$ & 6.20 & 0.41 & 5.81 & 0.41 & 6.00 & 0.42 \\
\hline & G & 8.38 & 0.48 & 7.84 & 0.45 & 8.14 & 0.46 \\
\hline \multirow[t]{8}{*}{ M2 } & $\mathrm{O}$ & 3.43 & 0.30 & 3.12 & 0.51 & 3.30 & 0.40 \\
\hline & A & 3.65 & 0.33 & 3.74 & 0.42 & 3.64 & 0.37 \\
\hline & B & 4.35 & 0.33 & 4.74 & 0.46 & 4.38 & 0.38 \\
\hline & C & 5.59 & 0.44 & 5.84 & 0.44 & 5.75 & 0.42 \\
\hline & $\mathrm{D}$ & 7.45 & 0.52 & 7.78 & 0.54 & 7.62 & 1.05 \\
\hline & $\mathrm{E}$ & 9.35 & 0.56 & 9.74 & 0.52 & 9.52 & 1.10 \\
\hline & $\mathrm{F}$ & 10.84 & 0.60 & 11.46 & 0.56 & 11.13 & 1.15 \\
\hline & G & 12.92 & 0.60 & 13.74 & 0.60 & 13.42 & 1.20 \\
\hline
\end{tabular}

differences. Smoothed cumulative distribution curves for maturity data modified for age prediction for this stage stages D, E and F of M2 (sexes pooled) are shown. These is shown as a triangle. The age interval for individuals curves represent the increasing proportion of children at 'in' stage D, extends from the youngest child in stage D, each age who have reached or passed the specific stage. up to the age when the most delayed child leaves this A tooth is considered to be 'in' a stage until it enters the stage and enters the next stage (when all individuals have next stage. The shaded area shows the age interval of all entered stage E). The age range of individuals within individuals within stage D; ranging from the youngest stage D and E are marked. The $51 \%$ age coverage for stage (most dentally advanced) to the oldest individual in that $\mathrm{D}$ is also shown. This figure was chosen for the forensic stage (most dentally delayed). Maturity is a continuum and odontologist where the burden of proof is 'on the balance we arbitrarily divide this into discrete stages, even though of probabilities.' This is an expression of the probability the process of maturation is gradual. Stage D in molars is of estimated age being on one side of an age threshold. defined as crown complete with initial root spicules visible If an individual of unknown age presents with a second at the mesial and distal edges. These root spicules increase permanent molar in stage D (crown complete with initial in length and the root bifurcation becomes visible, firstly root), the $51 \%$ age interval (from Table 3 ) is 7.01 to 8.50 . On as a dot or line, then as a semi-lunar radio-opacity. Once the balance of probabilities, the age of this individual is this occurs, the tooth is deemed to be in stage E. The three older than six but younger than nine.

types of tooth data in this study are summarised in Figure

The existence of population differences in dental 5. Mean age at entry for M2 stage D is shown as a dot, maturity is unclear and uncertain. Many studies report 
TABLE 3.Fifty one percent coverage for mandibular tooth stages ${ }^{1}$

\begin{tabular}{|c|c|c|c|c|c|c|c|c|c|c|}
\hline \multirow[b]{2}{*}{ Tooth } & \multirow[b]{2}{*}{ Grade } & \multicolumn{3}{|c|}{ Males $(\mathrm{n}=4,710)$} & \multicolumn{3}{|c|}{ Females $(\mathrm{n}=4,661)$} & \multicolumn{3}{|c|}{ Combined $(\mathrm{n}=9,371)$} \\
\hline & & $\mathrm{n}$ & $24.5 \%$ & $75.5 \%$ & $\mathrm{n}$ & $24.5 \%$ & $75.5 \%$ & $\mathrm{n}$ & $24.5 \%$ & $75.5 \%$ \\
\hline \multirow[t]{4}{*}{ I1 } & $\mathrm{D}$ & 222 & 3.62 & 4.70 & 162 & 3.49 & 4.48 & 384 & 3.54 & 4.58 \\
\hline & $\mathrm{E}$ & 425 & 4.73 & 5.91 & 297 & 4.58 & 5.60 & 722 & 4.67 & 5.80 \\
\hline & $\mathrm{F}$ & 308 & 6.05 & 7.03 & 269 & 5.80 & 6.83 & 577 & 5.98 & 6.99 \\
\hline & G & 561 & 7.25 & 8.57 & 460 & 7.01 & 8.09 & 1021 & 7.10 & 8.30 \\
\hline \multirow[t]{5}{*}{ I2 } & C & 42 & 3.38 & 4.21 & 29 & 2.83 & 4.05 & 71 & 3.06 & 4.10 \\
\hline & $\mathrm{D}$ & 386 & 4.08 & 5.20 & 253 & 3.80 & 4.95 & 639 & 3.98 & 5.03 \\
\hline & $\mathrm{E}$ & 425 & 5.39 & 6.60 & 335 & 5.10 & 6.19 & 770 & 5.23 & 6.46 \\
\hline & $\mathrm{F}$ & 428 & 6.96 & 8.00 & 353 & 6.50 & 7.64 & 781 & 6.72 & 7.95 \\
\hline & G & 684 & 8.01 & 9.54 & 643 & 7.67 & 8.97 & 1327 & 7.90 & 9.10 \\
\hline \multirow[t]{5}{*}{ C } & C & 327 & 3.85 & 5.01 & 173 & 3.52 & 4.62 & 500 & 3.71 & 4.93 \\
\hline & $\mathrm{D}$ & 512 & 5.00 & 6.51 & 370 & 4.72 & 5.96 & 882 & 4.92 & 6.27 \\
\hline & E & 745 & 6.99 & 8.40 & 542 & 6.46 & 7.78 & 1287 & 6.79 & 8.06 \\
\hline & $\mathrm{F}$ & 1063 & 8.97 & 10.60 & 995 & 8.00 & 9.58 & 2058 & 8.43 & 10.06 \\
\hline & G & 800 & 11.02 & 12.97 & 817 & 10.00 & 11.65 & 1617 & 10.44 & 12.30 \\
\hline \multirow[t]{7}{*}{ P1 } & A & 20 & 2.57 & 3.34 & & & & 21 & 2.59 & 3.33 \\
\hline & B & 69 & 3.33 & 4.26 & 55 & 3.01 & 3.79 & 124 & 3.10 & 4.07 \\
\hline & C & 433 & 4.38 & 5.44 & 308 & 4.18 & 5.28 & 741 & 4.28 & 5.40 \\
\hline & D & 554 & 5.95 & 7.20 & 406 & 5.60 & 6.95 & 960 & 5.78 & 7.05 \\
\hline & E & 803 & 7.67 & 9.00 & 795 & 7.20 & 8.53 & 1598 & 7.47 & 8.96 \\
\hline & F & 918 & 9.40 & 11.00 & 889 & 8.90 & 10.54 & 1807 & 9.05 & 10.92 \\
\hline & G & 580 & 11.32 & 12.97 & 657 & 10.63 & 12.10 & 1237 & 10.96 & 12.70 \\
\hline \multirow[t]{8}{*}{ P2 } & $\mathrm{O}$ & 10 & 2.39 & 4.92 & & & & 16 & 2.67 & 4.52 \\
\hline & A & 89 & 3.54 & 4.72 & 77 & 3.30 & 4.44 & 166 & 3.45 & 4.60 \\
\hline & B & 222 & 4.27 & 5.21 & 160 & 4.19 & 5.33 & 382 & 4.23 & 5.23 \\
\hline & C & 446 & 5.17 & 6.68 & 338 & 5.06 & 6.48 & 784 & 5.10 & 6.58 \\
\hline & D & 570 & 6.70 & 8.10 & 494 & 6.61 & 7.96 & 1064 & 6.66 & 8.01 \\
\hline & E & 769 & 8.06 & 9.87 & 744 & 7.86 & 9.05 & 1513 & 7.99 & 9.46 \\
\hline & $\mathrm{F}$ & 945 & 9.98 & 11.97 & 969 & 9.64 & 11.39 & 1914 & 9.83 & 11.76 \\
\hline & G & 626 & 12.00 & 13.98 & 708 & 11.32 & 13.29 & 1334 & 11.70 & 13.74 \\
\hline \multirow[t]{4}{*}{ M1 } & D & 131 & 3.31 & 4.22 & 100 & 3.22 & 4.03 & 231 & 3.25 & 4.14 \\
\hline & E & 358 & 4.47 & 5.42 & 247 & 4.25 & 5.23 & 605 & 4.39 & 5.38 \\
\hline & $\mathrm{F}$ & 432 & 5.66 & 9.53 & 313 & 5.42 & 6.56 & 745 & 5.56 & 6.90 \\
\hline & G & 1279 & 7.70 & 9.53 & 1187 & 7.28 & 9.00 & 2466 & 7.50 & 9.20 \\
\hline \multirow[t]{8}{*}{ M2 } & $\mathrm{O}$ & & & & 19 & 2.89 & 3.91 & 28 & 3.11 & 4.28 \\
\hline & A & 66 & 3.68 & 4.49 & 42 & 3.54 & 4.56 & 108 & 3.60 & 4.52 \\
\hline & B & 215 & 4.31 & 5.05 & 175 & 4.08 & 5.00 & 390 & 4.20 & 5.02 \\
\hline & C & 562 & 5.39 & 6.78 & 402 & 5.28 & 6.65 & 964 & 5.32 & 6.72 \\
\hline & D & 799 & 7.10 & 8.70 & 791 & 6.98 & 8.30 & 1590 & 7.01 & 8.50 \\
\hline & E & 794 & 8.98 & 10.48 & 734 & 8.57 & 10.01 & 1528 & 8.80 & 10.25 \\
\hline & F & 572 & 10.55 & 12.03 & 629 & 10.04 & 11.59 & 1201 & 10.25 & 11.97 \\
\hline & G & 983 & 12.53 & 14.50 & 1096 & 11.97 & 13.98 & 2079 & 12.02 & 14.11 \\
\hline
\end{tabular}

${ }^{1}$ This age interval includes $51 \%$ of individuals within each stage. Stage included if $n \geq 10$

significant differences in average age within tooth stage that a minimum age of 7 is too old to calculate the average between groups, but this is inappropriate to compare age for this stage. Significant differences between groups maturity or average age at entry. For example, imagine if have also been shown using a single dental maturity score the minimum age of a study was 7 and the average age at such as Nolla (Nolla, 1960) or Demirjian (Demirjian et al., entry of M2 stage D is calculated. Looking at Figure 5, this 1973; 1976; Demirjian, 1994). These have been interpreted will exclude many individuals younger than 7 who have as due to either a secular trend or regional differences entered this stage. Looking at the cumulative incidence in dental maturation but little attempt has been made to curve for stage $\mathrm{D}$, it is clear that more than half of 7 years old investigate this more fully. There is little doubt that these in this large study have M2 in stage D (or later), indicating differences occur, but it is questionable if they have any 


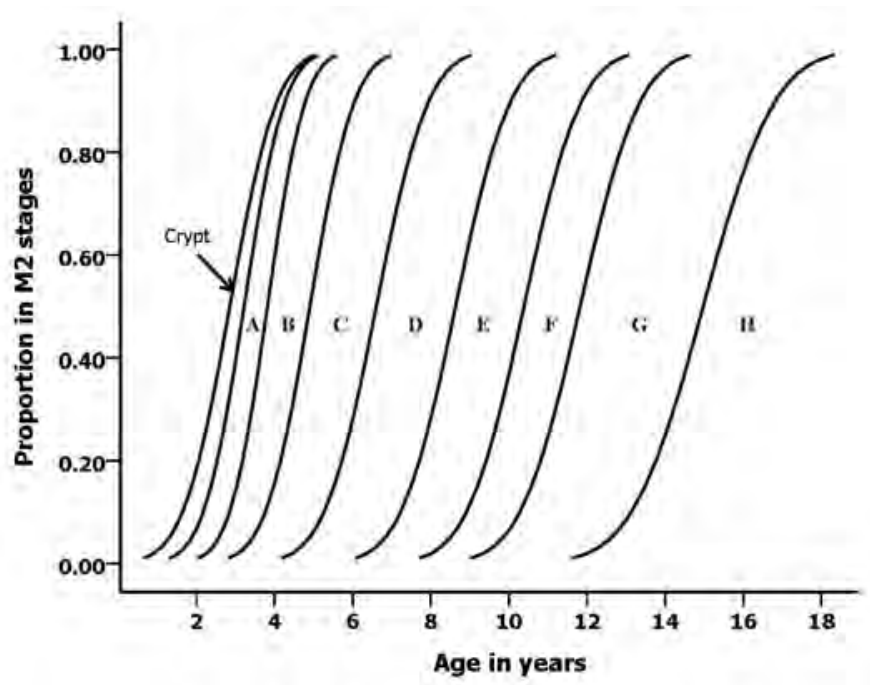

Fig. 3. Smoothed cumulative distribution curves (proportion of individuals and age) for stages crypt to $\mathrm{H}$ for the permanent mandibular second molar (sexes pooled).

biological meaning.

The time interval between the original study Demirjian et al. (1973) and the present collaboration is between twenty to forty years. Mean age at entry of individual tooth stages in girls from the Canadian reference (triangles apex at bottom; Demirjian and Levesque, 1980) and this study (triangles apex at top) are shown in Figure 6. The largest differences occur as a single stage difference in four teeth; the earliest stage with data for both incisors and canine and the second stage for first premolars with mean age in the recent study being later than the original reference. The mean ages in subsequent stages in these teeth are similar or close in age. A comparison of the most mature stage in all tooth types is similar or marginally earlier in the recent study compared to the reference. It is unclear what these

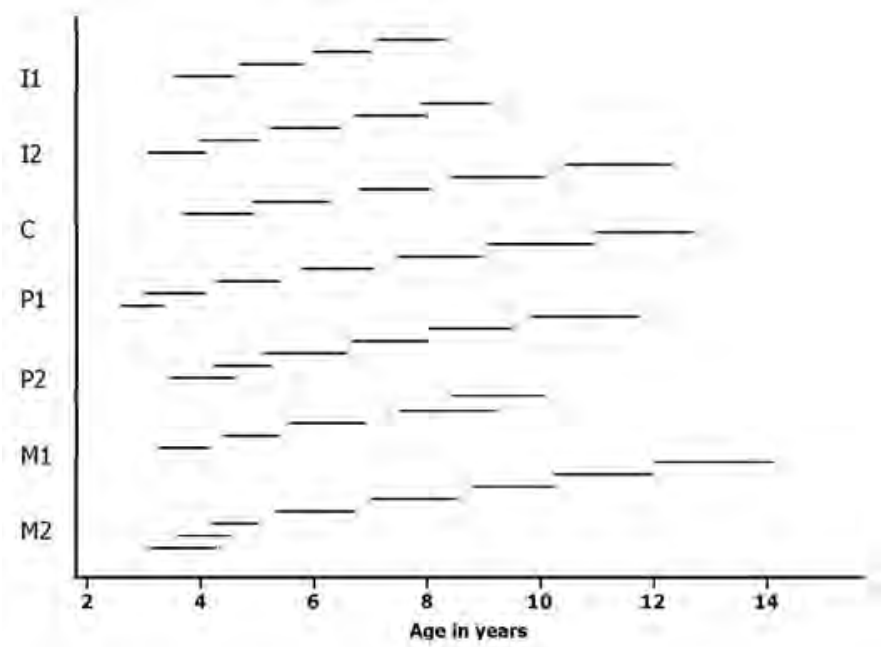

Fig. 4. Age interval of $51 \%$ coverage for stages A to G of permanent teeth (pooled sex). differences and similarities indicate, but no clear pattern or developmental shift is evident.

Most studies of dental maturity are based on children of European origin. Mean age at entry for individual tooth stages was compared in the groups of this collaborative study. Children in Canada, Finland, Sweden, Belgium, England, France, Australia and a small group from Korea showed a wide age range of individuals within each tooth stage with many similarities in average age at entry (Liversidge et al., 2006). No single tooth type was consistently earlier or later and no clear pattern emerged from this analysis. A comparison of mean age at entry of tooth stages by Moorrees et al. (1963) on White and Bangladeshi children aged 2 to 22 in London, United Kingdom showed few significant differences in mean age between these ethnic groups (Liversidge 2009). The lack of published data of dental maturity from other regions of the world is sparse, but being addressed. Preliminary results from a worldwide comparative study showing stage $\mathrm{H}$ (apex mature) of the mandibular first molar in girls is shown in Figure 7. Smoothed cumulative distribution curves and 95\% confidence interval of mean age (calculated from one year age groups using probit regression) are shown from the following regions: Australian Aboriginal (Liversidge and Townsend, 2006), Inuit, Japanese, Maori and Pacific Islanders (Moananui et al., 2008), South African Black and Cape Coloured, UK, Bangladeshi and White (Liversidge, 2009). The most advanced girls (youngest) girls in this stage are 6 years old and by 12, almost all have reached this stage. The average age at entry, when $50 \%$ of girls have reached this stage, is similar between groups, although two groups are slightly earlier than the others.

These similarities between the reference study and the present study and between world groups are supported by recent histological findings in the duration of crown formation (Reid and Dean 2006) between the past and the present. For instance, molar crowns take around 3 to 3.4 years to develop in maxillary, mandibular, first, second and third molars from Medieval Danes, northern European, South African Black and North American groups (Reid and Dean, 2006). The largest permanent crowns are found in Australian aborigines and the duration of enamel formation in molars in three first molars from this group is from 3 to 3.5 years (pers. comm. DJ Reid). Despite little documentation of the rate of dentine growth and root formation between individuals or groups, these findings suggest that the time it takes to grow a tooth is similar across time and between groups, especially at the resolution of crown and root fractions from radiographs.

Assessing maturity or estimating age from crown and root stages is usually used for an individual child. In this regard the individual is compared to reference data while, in human biology, differences between groups are of interest. Small differences in the mean age of individual tooth stages at the group level have little influence on the estimated age for an individual. Population specific reference data of radiographic tooth stages may be 


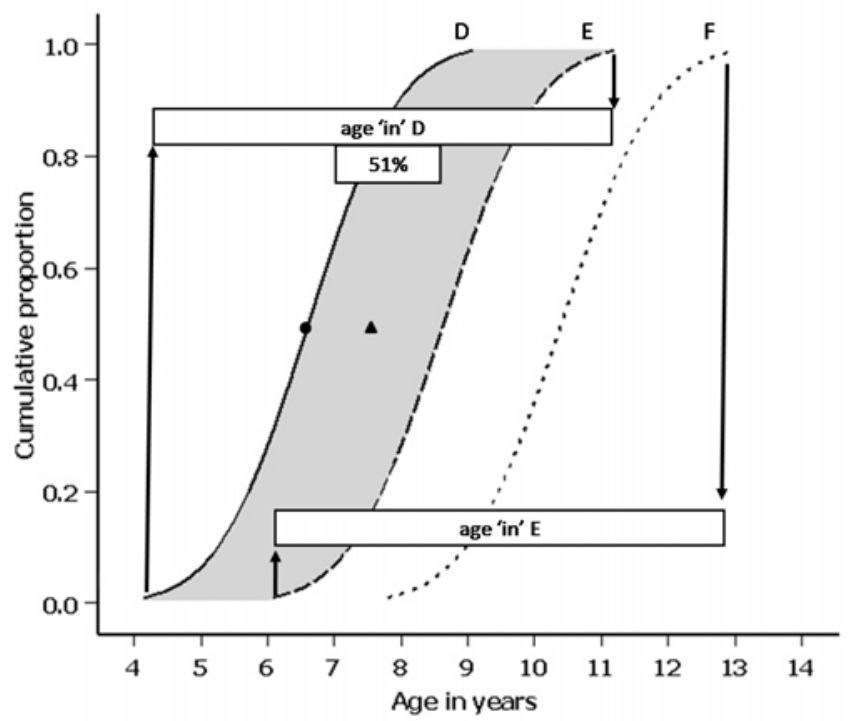

Fig. 5. A comparison of maturity data and within stage data. Smoothed cumulative distribution curves for stages $\mathrm{D}, \mathrm{E}$ and $\mathrm{F}$ for second molars are shown. Mean age of attainment and modified for age prediction are shown as dot and triangle respectively. Shaded area is the age interval of individuals within stage D. Age range within stage $\mathrm{D}$ and $\mathrm{E}$ are shown as well as $51 \%$ age coverage for stage D.

unnecessary and until evidence is available to show otherwise, the methods of age estimation presented here are appropriate for individuals from all groups.

\section{CONCLUSIONS}

New data on the timing of Demirjian stages from a large sample are presented in several ways. Two of these (modified maturity data, average age within stage from a uniform aged group) are new methods appropriate to estimate age from individual permanent teeth. The 51\% coverage age interval for individual tooth stages are described for forensic age estimation where the burden of proof is on the balance of probabilities. These results represent the biggest data set and therefore probably the most reliable maturity reference and age estimation methods for mandibular permanent tooth formation using Demirjian stages in humans.

\section{ACKNOWLEDGMENTS}

I am particularly grateful to Nils Chaillet (CHU SainteJustine Research Centre, University of Montreal, Montreal, Quebec, Canada) for inviting collaboration and also Marjatta Nyström, Hakan Mörnstad, Kian Rowlings, Jane Taylor, Guy Willems and their co-authors for sharing data.

\section{LITERATURE CITED}

Cameron N. 2004. Measuring maturity. Methods in Human growth research. In: Hauspie RC, Cameron N, Molinari L, editors. Cambridge: Cambridge University Press. p
108-140.

Chaillet N, Demirjian A. 2004. Dental maturity in South France: A comparison between Demirjian's method and polynomial functions. J Forensic Sci 49:1059-1066.

Chaillet N, Nyström M, Demirjian A. 2005. Comparison of dental maturity in children of different ethnic origins: International maturity curves for clinicians. J Forens Sci 50:1164-1174.

Cole TJ. 2002. Growth references and standards. In: Human growth and development. Cameron N, editor. San Diego: Academic Press. p 383-413.

Demirjian A. 1993-94. Dental development. CD-ROM, Silver Platter Education. Montreal: University of Montreal.

Demirjian A, Goldstein H. 1976. New systems for dental maturity based on seven and four teeth. Ann Hum Biol 3:411-427.

Demirjian A, Goldstein H, Tanner JM. 1973. A new system of dental age assessment. Hum Biol 45:211-227.

Demirjian A, Levesque GY. 1980. Sexual differences in dental development and prediction of emergence. J Dent Res 59:1110-1122.

Eveleth PB, Tanner JM. 1990. Worldwide variation in human growth. Cambridge: Cambridge University Press.

Kataja M, Nyström M, Aine L. 1989. Dental maturity standards in southern Finland. Proc Finn Dent Soc 85:187-197.

Konigsberg LW, Frankenberg SR. 1992. Estimation of age structure in anthropological demography. Am J Phys Anthropol 89:235-256.

Konigsberg LW, Herrmann NP, Westcott DJ, Kimmerle EH. 2008. Estimation and evidence in forensic anthropology: age-at-death. J Forensic Sci 53:541-557.

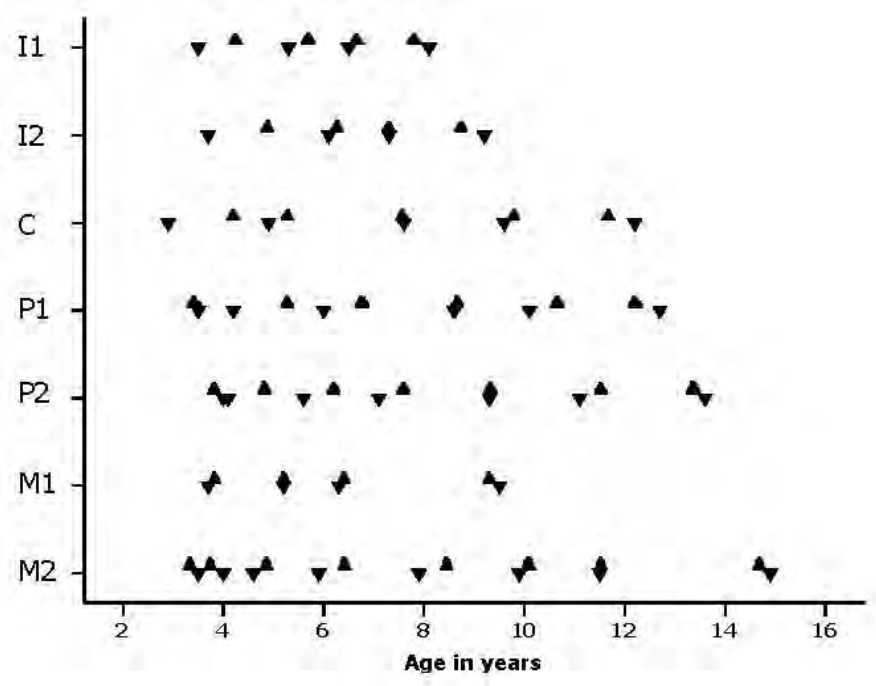

Fig. 6. A comparison of mean age entering tooth stages for girls from Demirjian and Levesque (1980) triangles apex down and Liversidge et al. (2006) triangles apex up. 


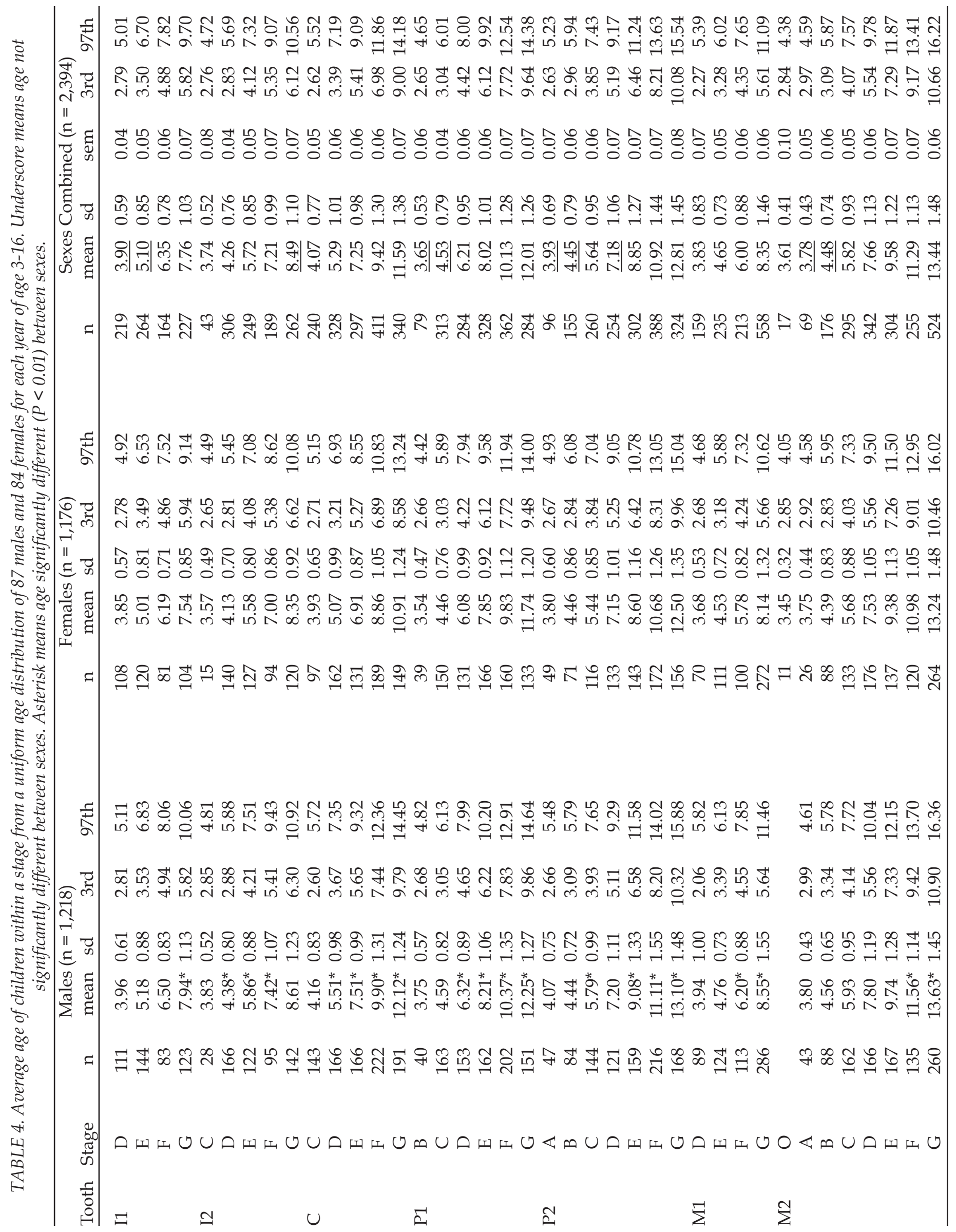



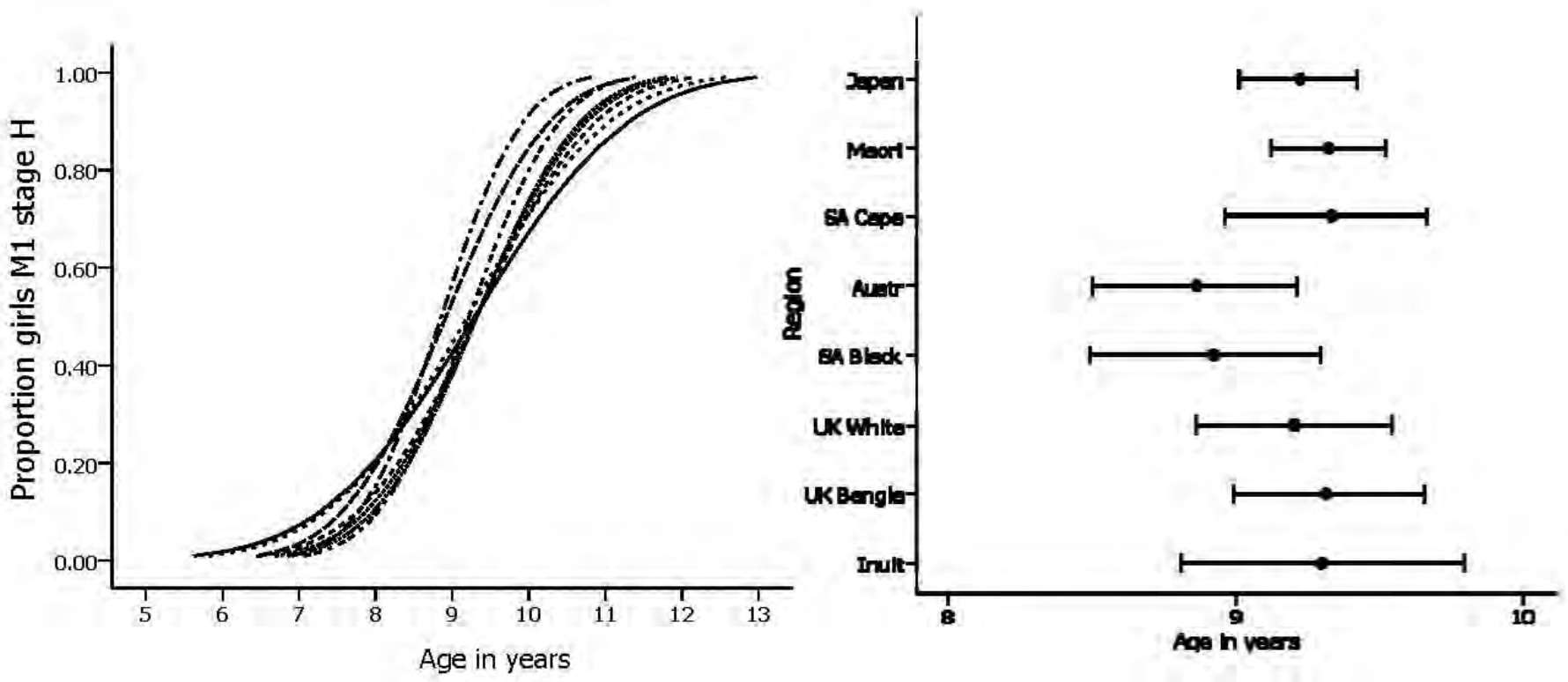

Fig. 7. Preliminary results of maturation of stage $\mathrm{H}$ of the mandibular first molar from world regions. Left: smoothed curves (proportion of girls vs. age). Right: 95\% confidence interval of mean age for Australian Aborigine, Inuit, Japanese, Maori and Pacific Islanders, South African Black, South African Cape Coloured, UK Bangladeshi, UK White girls.

Liversidge HM. 2003. Worldwide variation in human dental development. In: Thompson JL, Nelson A, Krovitz G, editors. Growth and development in the genus Homo. Cambridge: Cambridge University Press. p 73-113.

Liversidge HM. 2008. Dental age revisited. In: Irish JD, Nelson GC, editors. Technique and application in dental anthropology. Cambridge: Cambridge University Press. p 234-265.

Liversidge HM. 2009. Permanent tooth formation as a method of estimating age. Front Oral Biol 13:153-157.

Liversidge HM, Chaillet N, Mörnstad H, Nyström M, Rowlings K, Taylor J, Willems G. 2006. Timing of Demirjian tooth formation stages. Ann Hum Biol 33: 454-470.

Liversidge HM, Smith BH, Maber M. 2010. Bias and accuracy of age estimation using developing teeth in 946 children. Am J Phys Anthropol (doi:10.1002/ ajpa.21349).

Liversidge HM, Speechly T. 2001. Growth of permanent mandibular teeth of British children aged 4-9 years. Ann Hum Biol 28:256-262.

Liversidge HM, Townsend G. 2006. Tooth formation in Australian Aborigines. In: Zadzinska E, editor. Current trends in dental morphology research. Lodz: University of Lodz Press. p 405-410.

Maber M, Liversidge HM, Hector MP. 2006. Accuracy of age estimation of radiographic methods using developing teeth. Forensic Sci Int 159:S68-73.

McKenna CJ, James H, Taylor JA, Townsend GC. 2002. Tooth development standards for South Australia. Aust Dent J 47:223-227.
Moananui RT, Kieser JA, Herbison P, Liversidge HM. 2008. Advanced dental maturation in New Zealand Maori and Pacific Island children. Am J Hum Biol 20:43-50.

Moorrees CFA, Fanning EA, Hunt EE. 1963. Age variation of formation stages for ten permanent teeth. J Dent Res 42:1490-1502.

Nolla CM. 1960. The development of the permanent teeth. J Dent Child 27:254-266.

Nyström M, Haataja J, Kataja M, Evalahti M, Peck L, Kleemola-Kujala E. 1986. Dental maturity in Finnish children, estimated from the development of seven permanent mandibular teeth. Acta Odontol Scand 44:193-198.

Nyström M, Ranta R, Kataja M, Silvola H. 1988. Comparisons of dental maturity between the rural community of Kuhmo in north eastern Finland and the city of Helsinki. Commun Dent Oral Epidemiol 16:215-217.

Reid DJ, Dean MC. 2006. Variation in modern human enamel formation times. J Hum Evol 50:329-346.

Smith BH. 1991. Standards of human tooth formation and dental age assessment. In: Kelly MA, Larsen CS, editors. Advances in dental anthropology. New York: Wiley-Liss. p 143-168.

Taranger J. 1976. Evaluation of biological maturation by means of maturity criteria. Acta Paediatr Scand 258, suppl, 77-82.

Teivens A, Mörnstad H. 2001. A comparison between dental maturity rate in the Swedish and Korean populations using a modified Demirjian method. J Forensic Odontostomatol 19:31-35.

Willems G, Van Olmen A, Spiessens B, Carels C. 2001. Dental age estimation in Belgian children: Demirjian's technique revisited. J Forensic Sci 46:893-895. 